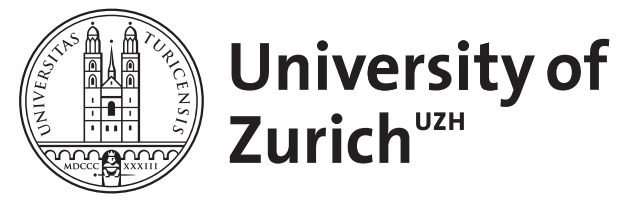

Zurich Open Repository and Archive

University of Zurich

University Library

Strickhofstrasse 39

CH-8057 Zurich

www.zora.uzh.ch

Year: 2013

\title{
One world health: Socioeconomic burden and parasitic disease control priorities
}

\author{
Torgerson, P R
}

DOI: https://doi.org/10.1016/j.vetpar.2013.04.004

Posted at the Zurich Open Repository and Archive, University of Zurich ZORA URL: https://doi.org/10.5167/uzh-78235

Journal Article

Accepted Version

Originally published at:

Torgerson, P R (2013). One world health: Socioeconomic burden and parasitic disease control priorities. Veterinary Parasitology, 195(3-4):223-232.

DOI: https://doi.org/10.1016/j.vetpar.2013.04.004 
One world health: socioeconomic burden and parasitic disease control priorities

Paul R. Torgerson

Section of Epidemiology, Vetsuisse faculty, University of Zurich, Winterthurestrasse 270, 8057 Zurich,

5 Switzerland

email: paul.torgerson@access.uzh.ch 


\begin{abstract}
10 Parasitic diseases present a considerable socio-economic impact to society. Zoonotic parasites can result in a considerable burden of disease in humans and substantive economic losses to livestock populations. Ameliorating the effects of these diseases may consist of attempts at eradicating specific diseases at a global level, eliminating them at a national or local level or controlling the disease to minimise incidence. Alternatively with some parasitic zoonoses it may only be possible to treat human

15 and animal cases as they arise. The choice of approach will be determined by the potential effectiveness of a disease control programme, its cost and the cost effectiveness or cost benefit of undertaking the intervention. Furthermore human disease burden is being increasingly measured by egalitarian nonfinancial measures which do not sit comfortably with measurements of economic costs in livestock. This adds additional challenges to assessing socio-economic burdens of zoonotic diseases. Using 20 examples from the group of neglected zoonotic diseases, information regarding the socio-economic effects of these diseases are reviewed and the use of this information in decision making with regard to control and treatment of these diseases is discussed.
\end{abstract}

Key words: Parasitic zoonoses, socio economic burden, cost effectiveness 


\section{1. Introduction}

One Health is dedicated to improving the lives of all species — human and animal—-through the integration of human medicine, veterinary medicine and environmental science. The concept of "One Health" has evolved from “One Medicine," an idea which originated from the veterinary epidemiologist Calvin Schwabe in the 1960s to demonstrate that there are no major conceptual

30 differences between human and veterinary medicine, and that integrated work should be promoted (Schwabe, 1984) In 2005 it was estimated that of 1407 species of recognised human pathogens, 58\% were zoonotic (Woolhouse and Gowtage-Sequeria, 2005) illustrating the need for a one health approach to many human and animal diseases. Many upper income countries have controlled or eliminated a number of animal and zoonotic diseases through expensive intervention programmes. Different disease

35 priorities and resource availability exist in low income countries, whilst in high income countries increased livestock intensification and public health interventions may render some continuing programmes redundant.

As veterinary parasitologists, we are interested in parasitic diseases that impact on animal health and in parasitic zoonoses. However, we live in a world of limited resources and therefore it is

40 important to prioritize resources to limit the impact of these diseases. In this article I would like to summarize how a number of tools can be used to define the socio economic burden of diseases on society, and how this evidence can be used to develop disease control priorities illustrated with reference to a number of neglected zoonoses and "non-neglected" zoonoses

For a number of zoonoses the state has assumed responsibility for intervention to decrease

45 disease incidence. This may be a control or elimination programme although never an eradication programme as the latter term is widely misused. "Control" is defined as the reduction of disease incidence, prevalence, morbidity, or mortality to an acceptable level, as determined by the country or area in question. "Elimination" is defined as the reduction of disease incidence to zero in a defined geographic area. Once elimination has been achieved it requires ongoing public health measures to 
50 prevent disease re-emergence "Eradication" is defined as the reduction of disease incidence globally to zero (Dowdle, 1998). The distinction is important. For example despite the claim that Echinococcus granulosus appears to have been "eradicated" from New Zealand (Davidson, 2002), it has actually been eliminated as on-going measures are required to maintain the country free from the parasite. If global eradication had been achieved then these measures would no longer be necessary. Rhinderpest, which

55 for millennia was considered to be the animal disease with the greatest impact on human well-being, has been eradicated (Mariner et al., 2012). Hence no further measures to control this disease are required anywhere.

The control or elimination, at least on a nationwide basis, of zoonotic diseases are laudable aims, but we should remain critical of such programmes, which are often expensive and can cause

60 major bystander effects to livestock producers that may be worse that the original problem. If the aim is the protection of public health, programmes should be evaluated not only to ensure they are doing so, but also to ensure they are doing so in a cost effective manner. They should also remain competitive relative to other forms of public health intervention such as investing in the control of other diseases or indeed building hospitals. With zoonoses there is also the additional major benefit of reducing animal

65 health losses which should be factored into the analysis. This may result in a disease having a higher priority then purely its impact on human health. The dual socio-economic costs to human health and the livestock industries can also lead to challenges in calculating the impact of these diseases on societies as human disease burden and animal disease costs may be measured by very different and incompatible methodologies (Carabin et al., 2005).

\section{Socio-economic burden of a disease.}

This can broadly be defined as the impact a disease has on society measured by financial cost, mortality, morbidity or other indicators. To be able to assess the impact of any disease we need to be able to measure it. With parasitic diseases that have an impact on agricultural animals the financial 
75 impact of these diseases is the most important metric. However in resource poor countries animal disease will also have an indirect impact on human health through financial hardship or malnutrition. Livestock have many values to society including direct production of food, their use in agricultural production (such as draft power or sources of manure), as a deposit of wealth, and valuable cultural benefits. Loss of livestock through disease can impact in these areas. In high income countries

80 livestock are mainly treated as a financial asset and one of many sources of food. In low income countries animals have a range of functions. When livestock losses occur due to disease the direct costs can be estimated using market prices. Indirect costs are more difficult to estimate, but may be more important than the direct financial costs.

To estimate the societal burden of zoonoses, methods are needed to combine the adverse effects

85 on society of disease and reduced productivity in livestock with those of disease and lower levels of well-being and productivity in people. Direct costs to human health include the costs of death, sickness and injury and the costs of treating the disease. Indirect costs include the loss of wages to workers who are sick and the reduced productivity of workers who may have sub-clinical effects of disease. The various methods for measuring the cost or impact of parasitic zoonoses are discussed extensively by

90 Carabin et al. (2005).

\subsection{Disability adjusted life years}

This is a measure of human population health that combines mortality and morbidity into one unit to measure the impact of a disease on society. It is a composite measure and can be written as

\section{DALY $=$ YLL + YLD}

Where YLL is the years of life lost due to premature mortality. This can be calculated from the the life expectancy at the age of death which is generally drawn from the Coale-Demeny Model Life Table West which can be downloaded from the WHO website (http://www.who.int/entity/healthinfo/bodreferencestandardlifetable.xls). The YLD is the years of life 
100 lived with a disability and is the number of health years of life lost weighted by the severity of the condition. Simple examples can be used to demonstrate how a DALY is calculated. A healthy male of age 50 years would have a life expectancy of an additional 31 years. Thus if he were to suffer sudden death resulting from anaphylaxis due to a ruptured hydatid cyst he would loose 31 years of healthy life or 31 YLLs. Since death was sudden there is no time lived with a disability and hence the total numbers

105 of DALYs lost is 31 . On the other hand if he was infected with neurocysticercosis resulting in epilepsy and this epilepsy remained untreated, he might still be expected to live 31 years. Untreated epilepsy has a mean disability weight of 0.15 (Murray, 1996) and hence the numbers of YLLs lost is zero, but he loses $0.15 * 31$ YLDs or 4.65 YLDs or a total of 4.65 DALYs. The disability weight varies with the function of the patient and can be estimated by a variety of techniques, including a time trade off such

110 as undertaking a study over a population of individuals and asking them how many years they would trade at a certain level of disability to be in complete health (Schwarzinger et al., 2003). Thus an average 50 year old male with epilepsy of average severity would be prepared to trade 4.65 years of healthy life (or $15 \%$ of his remaining life expectancy) to be "cured" of epilepsy. At a population level the numbers of DALYs lost to echinococcosis or cysticercosis would be estimated from the incidence

115 of fatalities in each age group and gender to calculate the YLLs and similarly the incidence and duration of sequelae and their disability weights for non-fatal outcomes.

The effectiveness of intervention strategies can be calculated as the number of DALYs estimated to occur due to a given condition in the absence of intervention minus the number of DALYs expected if control measures were implemented. However, this disregards any additional benefits of

120 disease control to agriculture (e.g. anthelmintic treatment of dogs reduces cystic echinococcosis incidence in both humans and sheep). Nevertheless, if a total societal financial analysis is undertaken, the true cost-effectiveness of control, in terms of DALYs saved, can be estimated by implementation of cost sharing between sectors proportional to each sector's overall benefit (Roth et al., 2003). 


\section{3. Neglected parasitic zoonoses}

There are a number of neglected parasitic zoonoses. At an initial meeting on neglected zoonoses at WHO in 2005 a list of 7 neglected zoonoses were agreed (WHO, 2006). These were echinococcosis, rabies, brucellosis, bovine tuberculosis, zoonotic trypansomosis, cysticercosis and anthrax. By 2010, a further two parasitic zoonoses had been added to the list, namely fasciolosis and leishmaniosis.

130 Furthermore fish born trematodes, zoonotic schistosmiosis (Schistosoma japonicum) and toxoplasmosis were also suggested (WHO, 2011). These are, for the most part, diseases which have been present for centuries and which are usually associated with populations living in close proximity to their animals. These endemic zoonoses fall very much into the category of neglected diseases and as a result some are now re-emerging health problems. They affect the poorest communities. Because they also affect

135 livestock, causing lowered productivity or death, they not only attack peoples' health, but also their livelihoods. Using these as examples we can see how studies on the socio-economic burden of disease can be used to develop priorities for the control.

\subsection{Cystic Echinococcosis}

140 The burden of cystic echinococcosis (CE) caused by Echinococcus granulosus, both in terms of monetary burden and/or DALYs has been estimated globally as in a number of countries ( Torgerson et al., 2000, 2001, 2008, 2010; Torgerson and Dowling, 2001, Budke et al., 2004, 2006, Majorowski et al., 2005, Benner et al., 2010;Fasihi Harandi et al., 2012). The global burden of CE is over 1 million DALYs with a financial burden in excess of $\$ 1$ billion per annum (Budke et al., 2006). In many areas

145 the local burden of cystic echinococcosis is substantial; in some rural nomadic pastoralist communities such as in western China, echinococcosis may be one of the highest single causes of disease burden within the population (Budke et al., 2004). It has been shown that given certain circumstances, CE can be completely eliminated by aggressive and regular treatment of dogs with a cestocidal anthelmintic such as praziquantel, combined with dog control measures and veterinary supervion of the slaughter of 
150 livestock and other animals serving as intermediate host. Factors that facilitate complete elimination include the lack of a wildlife host and geographical isolation. This has resulted in successful programmes in New Zealand, Iceland, Tasmania, Cyprus and the Falkland islands (reviewed by Craig and Larrieu (2006) The same principles can be used in countries where there may be encroachment from non-control areas in neighbouring districts. Cost benefit studies of possible control programmes in

155 highly endemic areas such as China suggest that the financial return appears to be greater than the cost of implementation even if the local epidemiology does not allow total elimination. Likewise the cost per DALY averted is in the order of just \$10-\$12 (Budke et al., 2005) making it highly cost effective. However these calculations were made in a region which has amongst the highest prevalences of human echinococcosis, with certain Tibetan communities having a prevalence of $5-10 \%$ or more

160 (Budke et al., 2004). Similar studies would also be needed lower to confirm this in communities where the human burden is lower. CE should receive high priority as it has both a high global and local disease burden with economic costs in animals. There are also cost effective tools for control and elimination (Table 1). However, one place where elimination is not possible and control a challenge is in Australia because of the establishment of the cycle between dingoes and marsupials, both of which

165 seem to be highly susceptible to infection (Jenkins, 2006).

\subsection{Alveolar echinococcosis}

Alveolar echinococcosis (AE) is confined to the northern hemisphere. In some communities in China the disease has a very high local burden (Budke et al., 2004). In Europe and central Asia the

170 disease appears to be emerging in some localities (Schweiger et al., 2007, Nahorski et al 2013; Ussymbaeva et al., 2013 ). The global burden of disease has been estimated at about 666,000 DALYs per year (Torgerson et al., 2010) and thus the impact is high - mainly due to the high mortality rate as the number of new cases per year is approximately 18,000 . Over $90 \%$ of the burden is in China. In Switzerland there are between 20 and 30 new cases per year, resulting in an annual burden of 
175 approximately 77 DALYs (Torgerson et al., 2008). Because of the wildlife reservoir, and the cycle involving foxes and small mammals, control is a challenge and elimination is probably not possible with present technology. There is a major concern in Europe of increased risk of human infection resulting from the increased numbers of urban foxes (Deplazes et al., 2003; Schweiger et al., 2007). This has stimulated pilot control programmes to treat foxes and it has been shown that distributing fox

180 baits containing praziquantel on a regular basis can substantially reduce the prevalence of $E$.

multilocularis in foxes (Hegglin and Deplazes, 2008). The question remains as to the cost effectiveness of this intervention as it is still uncertain to what extent the human incidence is likely to decrease from such a programme. Treatment of cases as they arise is effective in high income countries with advanced health care, such as Switzerland and France (Torgerson et al., 2008; Piarroux et al., 2011;). Such

185 treatment in Switzerland costs about $€ 6000$ per DALY saved, which although expensive is cost effective in terms of the high GDP per head in Switzerland (Torgerson et al., 2008). In China, in regions where the human incidence is very high, dogs are likely to play a role in transmitting $E$. multilocularis to humans. Modelling studies have suggested that regular treatment of dogs with praziquantel in such endemic communities will result in the decrease in incidence of human AE.

190 However, this could be as little as 50\% reduction if the dog is acting as a conduit from the wild life cycle as treating dogs will not affect the biomass in the fox and rodent population. In contrast, if dogs are reinfecting small mammals in an anthropomorphic cycle, then regular treatment of dogs could reduce human AE by $90 \%$ or more (Budke et al., 2005) . Both scenarios are cost effective in reducing human disease in terms of \$ per DALY averted.

195

\subsection{Cysticercosis}

Human neurocysticercosis is highly endemic in many low and middle income countries where there is widespread pork consumption. It has been largely eliminated from high income countries through slaughter control. Of those diseases on the list of neglected zoonoses, it alone has the potential to be 
200 eradicated globally as the parasite life cycle specifically requires pigs and humans with no other hosts involved in transmission. The global burden of human cysticercosis is likely to be high. In a systematic review of 12 studies from Latin America, Sub-Saharan Africa and South-east Asia it has been estimated that $29.6 \%$ of individuals with epilepsy have neurocysticercosis (Ndimubanzi et al., 2010). In the context that the burden of epilepsy in low and middle income pork consuming countries is

205 approximately 6.8 million DALYs per annum, this indicates the very large burden due to Taenia solium cysticercosis globally (Torgerson and Macpherson, 2011). Several local studies have also indicated that this zoonosis has a substantial impact on endemic communities. In the Eastern Cape of South Africa, the annual monetary burden of cysticercosis has been estimated at between US \$ 18.6 million and US \$ 34.2 million (Carabin et al., 2006). In Mexico is has been estimated that neurocysticercosis results in

210 0.25 DALYs per 1000 person years (Bhattarai et al., 2012). With a population of 114 million this represents about 28,500 DALYs per year due to neurocysticercosis. A study in the West of Cameroon suggested that the burden of neurocysticercosis was 9 per 1000 person years (Praet et al., 2009). However this may be an over estimate as it is somewhat higher than the estimate for the burden of epilepsy (2.45 DALYs per 1000 person years ) in the Cameroon (Bhattarai et al., 2012). There are few documented formal programmes to control cysticercosis. In Henan province, China, it has been reported that mass anthelmintic treatment of humans reduced the prevalence of human taeniosis from $0.65 \%(16,159 / 2,480,419)$ in 1978 to $0.06 \%(8,583 / 13,901,265)$ in 1983 , with a corresponding decrease in the annual incidence of human cysticercosis from 31.4 cases per million to 1.3 cases per million (Wu et al., 2012). Elsewhere mass treatment with praziquantel or nicloseamide

220 has been demonstrated to be successful on a local scale (Flisser et al., 2011). Taenia solium has also been included in a priority list of six human diseases (polio, mumps, rubella, dracunculiasis, lymphatic filariasis and cysticercosis) targeted for global eradication (WHO, 2006). Therefore T. solium should receive the highest priority due to its high global burden and economic costs and the potential for eradication. 


\subsection{Human African Zoonotic Trypanosomiosis}

Human African zoonotic trypanosomiosis is caused by Trypanosoma brucei rhodesiense with reservoirs in both domestic and wild species (Fevre et al., 2008a). Human African trypanosomiosis

230 (HAT) has a burden of over 1.3 million DALYs, but perhaps less than $10 \%$ is due to the zoonotic T.b. rhodeiense. In Uganda, from a perspective of hospital based interventions alone, it costs approximately US\$8.50 per DALY averted for chemotherapy, nursing and associated costs of infected people (Fevre et al., 2008b). Case finding by screening in and around known foci of the disease is thus highly cost effective. Of great importance with zoonotic HAT, however, is the extension of the area of endemicity,

235 with parts of Uganda being at substantial risk of becoming co endemic with T. b. rhodensiense and T. $b$. gambiense which would greatly complicate efforts to control and treat this disease. Consequently, to prevent this scenario, a mass treatment programme of cattle with trypanocidal drugs was initiated in northern Uganda (Kabasa, 2007). This can also be combined with insecticides in both cattle and pigs to reduce levels of the tsetse fly vector.

Other programmes have included mass treatment of pigs, cattle and other potential reservoir hosts, which is beneficial to animal health and productivity. The lower incidence in animals reduces the costs of human trypanosomiosis as there are fewer patients to treat (Magona and Walubengo, 2011). Thus both human surveillance and treatment, and mass treatment of reservoir hosts are cost effective for the control of zoonotic HAT. So although in a global perspective the human burden of HAT is

245 modest, locally it can be high, especially since there may be widespread under-diagnosis of HAT. For example, febrile illnesses in many parts of Africa are often assumed to be malaria, resulting in cases of sleeping sickness going undiagnosed and receiving inappropriate treatment (WHO, 2011). In addition, there may be high economic costs to livestock and tools are available to ameliorate transmission, although there are few data on the cost effectiveness of such tools. Appropriate treatment of human 
cases is highly cost effective.

\subsection{Food borne trematodes}

A number of foodborne trematodes present a substantial burden for human health globally. Clinically

255 important trematode infections in humans include Clonorchis sinensis, Opisthorchis viverrini, Fasciola spp, Paragonimus spp and intestinal flukes (Sripa et al., 2010). It has been estimated that over 750 million people are at risk of infection with foodborne trematodes, with approximately 56 million infected at any one time. Of these, 7.9 million suffer severe sequelae and there are over 7000 deaths per year. This results in a global burden of 665,000 DALYs per annum (Fürst et al., 2012a).

\subsubsection{Fasciolosis}

Fasciolosis, caused by Fasciola hepatica or F. gigantica, has a widespread geographical range with a huge impact on livestock. However human fasciolosis tends to be more focal and is related to the consumption of certain plants that are contaminated with metacercariae. It is estimated that there are

265 approximately 2.65 million cases of human fasciolosis globally. Of these 2.50 million (94\%) are from either the Middle East (Egypt and Iran) or Latin America (Bolivia, Ecuador and Peru). The global burden of human disease is estimated to be 35,000 DALYs annually (Fürst et al. 2012a). Because of the rather low health impact to humans, control of fasciolosis is unlikely to be a cost-effective public health programme other than in a few communities which have high levels of endemicity (eg the Nile Delta).

270 However, fasciolosis is known to have a huge impact on livestock production. In Switzerland, with an estimated prevalence in cattle of between 15 and 20\% ( Rapsch et al., 2006), the disease has an annual impact of approximately $€ 52$ million per annum or $€ 255$ per infected animal (Schweizer et al., 2005). Reliable estimates for the global financial losses caused by Fasciola spp to the livestock industry are not available. However, Copeman and Copland (2008) estimated that in southern and eastern Asia 
275 estimated that between 51 and 118 million cattle or buffalo are infected with $F$. gigantica, resulting in annual economic losses of AU\$4 billion and AU\$11 billion per annum. This represents between 11 and $26 \%$ of large ruminants infected (over 452 million large ruminants). Therefore it can clearly be seen that the socio-economic burden of fasciolosis is mainly a livestock problem. However, effective control of the parasitic infection in livestock will avoid large livestock losses and will help to reduce the burden

280 of human disease in some localities.

\subsubsection{Clonorchiosis and Opisthorchiosis}

Clonorchis sinensis and Opisthorchis viverrini can induce cholelithiasis, cholestasis, cholangitis, cholecystitis, biliary and liver abscess and cirrhosis, pancreatitis, hepatitis, and cholangiocarcinoma.

285 Because of the potentially more severe sequelae including fatal carcinomas, these parasites represent a much greater burden to the human population that fasciolosis. It has been estimated that nearly 24 million people are infected globally with nearly 7000 deaths annually resulting in 350,000 DALYs annually (Fürst et al., 2012a). These are fish-borne zoonoses and control is largely through ensuring fish is well cooked prior to consumption improvement of sanitation to prevent parasite eggs reaching

290 fish habitats, and education (Fürst et al., 2012b) In farmed fish snail control and reducing contamination of ponds by eggs from infected definitive hosts has beneficial effects (Clausen et al., 2012). Praziquantel is the treatment of choice for infected humans (Fürst et al., 2012b), but there appears to be little evidence with regard to the cost effectiveness or cost benefit of any intervention strategies.

\subsubsection{Paragonimosis and intestinal flukes}

There are an estimated 23 million people globally infected with Paragonimus resulting in about 250 deaths annually at the cost of nearly 200,000 DALYs. (Fürst et al., 2012a). Intestinal flukes infect just under 7 million people resulting in an annual loss of approximately 84,000 DALYs. Intervention is 
similar to the control of chlonorchiosis including measures to prevent

infection in the freshwater crustaceans from which people acquire Paragonimus spp., and of

fish and water plants, which are the sources of human infections with Metagoniumus yokogawai and Fasciolopsis buski, respectively..

305

\subsection{Zoonotic schistosomiosis}

Most zoonotic cases of schistosomosis are due to $S$. japonicum. New disability weights given to $S$. japonicum (Finkelstein et al., 2008) and updated information on global prevalence (Van der Werf et al., 2003) indicate that the true burden of human schistosomosis is substantially higher than previously

310 thought and is currently estimated to be approximately 70 million DALYs annually (King and Dangerfield-Cha, 2008; Hotez and Fenwick, 2009;). If zoonotic schistosomosis is responsible for only a small proportion of this global burden, then it would still mean that this disease has one of the highest global burden of any parasitic zoonosis. S. japonicum currently is an important zoonosis in five provinces in China, where more than 50 million people are at risk and approximately one million

315 people and several hundred thousand livestock are infected (McManus et al., 2010). S. japonicum also occurs in 28 provinces in the Philippines and in discrete foci in the province of Central Sulawesi in Indonesia (King, 2009). Economic losses for infections in livestock have been seldom studied and hence are less defined, but add significantly to the economic burden and suffering of communities. It is known that the non-zoonotic $S$. bovis can result in substantial economic losses in livestock (Hunt

320 McCauley et al., 1984) and hence, by analogy, direct production losses due to $S$. japonicum are likely.

S. japonicum was successfully eliminated from Japan through snail control and socio-economic changes. The national schistosomosis control program in China is recognized as one of the most successful globally: the cornerstone of the programme is mass chemotherapy. S. japonicum is regarded by the Chinese authorities as being on par with HIV/AIDS, TB and hepatitis B as a public health 
325 problem (Wang et al., 2008). Integrated control will incorporate the use of human and bovine chemotherapy, health education/promotion, improved sanitation and focal use of molluscicides (Wang et al., 2009). Control and elimination of zoonotic Schistosoma species provides a serious challenge but successes already achieved show that it can be done.

330

\subsection{Leishmaniosis}

The most recent estimate of the global burden of leishmaniosis is approximately 2 million DALYs per annum (Lopez et al., 2006) of which a substantial but unknown proportion is of zoonotic origin.

There are challenges in reducing this burden through control or prevention. Altering the habitat of the

335 vectors and mammalian reservoir hosts to reduce transmission to people, would require extensive and expensive environmental management and would be difficult to implement and sustain. However new tools have been developed for the control of canine leishmaniosis, such as insecticide-impregnated collars and topical insecticides which should be integrated with stray dog control. No cost-effective or cost-benefits studies have been undertaken on such programmes to ameliorate human leishmaniosis.

340 Treatment of visceral leishmaniosis cases, such as in a relief programme, is highly cost effective and has been estimated at just US\$ 18.40 for each DALY averted (Greikspoor et al., 1999); any intervention that costs less than $\$ 25$ per DALY averted is considered very good value for money by the World Bank.

\subsection{Toxoplasmosis}

345 Toxoplasmosis is a global zoonosis and a rare example of a parasitic disease that still causes a high human health burden in high income countries. Congenital toxoplasmosis is an important syndrome that may affect an infant born to a mother exposed to Toxoplasma for the fist time during pregnancy. Congenital toxoplasmosis can result in a number of syndromes ranging from chorioretinitis to hydrocephalus and neurological deficits (Jones et al., 2001). Because congenital toxoplasmosis can 
result in foetal and neonatal death this leads to high numbers of years of life lost. This, combined with sequelae that may be severe and life long, also leads to high numbers of YLDs and hence a high burden in terms of DALYs. In the Netherlands congenital toxoplasmosis results in approximately 2300 DALYs lost per year (Kortbeek et al., 2009). In addition, toxoplasmosis is a well known complication of HIV infection and acquired toxoplasmosis can cause chorioretinitis and is being increasingly linked

355 to neurological and psychological disorders such as epilepsy, migraine and schizophrenia (Palmer, 2007; Koseoglu et al., 2009; Torrey et al., 2012). A substantial proportion of human toxoplasmosis is food-borne and one estimate from the Netherlands suggests it is amongst the most important foodborne diseases in terms of burden of disease (Havelaar et al., 2012). Toxoplasmosis generally appears to have a higher seroprevalence in low income countries and for this reason is likely to have a higher

360 disease burden in such countries. In addition, there appears to be more pathogenic genotypes circulating in Latin America with greater severity of sequelae (Gilbert et al., 2008). Presently, there is little that can be done in terms of control or elimination of this disease although seroprevalences are decreasing in many parts of the world (Pappas et al., 2009), possibly linked with increased living standards. In addition, with increased intensification of the pork industry there is a lower prevalence in

365 pork, with a lower risk of transmission to humans (Davies, 2011). At least in theory, transmission could be ameliorated by testing meat for toxoplasmosis and ensuring infected meat is frozen to destroy the bradyzoites prior to consumption (Kijlstra and Jongert, 2009). In addition, the disease burden could be lowered by modifying behaviour in high risk groups such as pregnant women or HIV positive subjects to lower or prevent transmission to these groups.

Toxoplasmosis can also cause significant livestock losses, particularly to the sheep industry. Infection of sheep with Toxoplasma gondii can result in early embryonic death and resorption, foetal death and mummification, abortion, stillbirth, and neonatal death. Severity of infection is associated with the stage of pregnancy at which the ewe becomes infected, the earlier in gestation, the more severe the consequences (Dubey, 2009). The magnitude of the economic damage this parasite causes to the 
375 sheep industry is not known, but one study in Uruguay in 1997 suggested that Toxoplasma-induced abortions resulted in losses amounting to between US\$1.4 million and US\$ 4.7 million per annum (Freyre et al., 1997). A commercial vaccine became available 20 years ago (Buxton and Innes, 1995) and can be used to reduce toxoplasmosis induced abortions in sheep flocks.

380

\section{4. "Underneglected" zoonoses}

There are a number of zoonotic diseases that are of low socio-economic significance, but continue to attract substantial investment due to reasons of trade in animal products, political reasons or in a misunderstanding of their true impact on society. Alternatively, changes in technology or animal

385 husbandry have resulted in eliminating animal to human transmission which was previously common, but policies for surveillance and control have not been amended to match the the now low or negligible public health risk. It can be argued that resources invested in the control of these zoonoses would produce a better return by investing in others that have a more substantive socio-economic impact.

\section{4.1. Taenia saginata}

T. saginata is completely dependent on humans for its transmission. However, unlike T. solium, the clinical effects of T. saginata are relatively trivial; usually at most limited to mild gastrointestinal signs and anal pruritis. With no fatalities and a very low disability weight, the global burden of disease due to T. saginata is vanishingly low, despite it being a common parasitic infection in some low-income countries. The direct economic costs in terms of human disease are consequently also very low and limited to the cost of treatment. In cattle there are limited studies on the economic costs of infection on production losses. However, in most high-income countries inspection of beef for the presence of bovine cysticercosis is compulsory. Carcasses shown to be infected may be condemned, or downgraded and refrigerated (Dorny and Praet, 2007). It is this downgrading that can cause substantive economic 
which are causing the economic losses. Furthermore, current routine meat inspection has a very low sensitivity (Geysen et al., 2007). Therefore most infected beef enters the human food chain regardless. Because of the very low burden of human disease, interventions in the food chain such as meat inspection prevent the loss of very few DALYs. However the cost of treatment is very low, so cost

405 effectiveness of treatment of individual human cases remains reasonable.

\subsection{Trichinella spp.}

Historically, meat controls for Trichinella spp. have been undertaken routinely in high-income countries and human trichinellosis was and is usually regarded as a severe human disease. However,

410 human trichinellosis appears to have a surprisingly low burden of disease, even in endemic countries with no routine meat controls. A systematic review by Murrell and Pozio (2011) suggested that the numbers of reported cases globally were very low with just 65,818 cases and 42 deaths reported from 41 countries between 1986 and 2009. Although likely to be an underestimate of the global incidence it still indicates that human disease is a rare event. However, in high income countries there is a large

415 financial investment in the control of Trichinella spp. Due to regulations in the European Union (EU) there is compulsory inspection of most pig carcasses, with estimates of as much as US\$570 million spent annually by the EU for inspection of pork (Pozio, 1998). However, this is likely to be an exaggeration as the cost estimate for inspection by pooled sample digestion is $0.15 €$ per pig (Kapel, 2005) and with 167 million pigs slaughtered per year, this would mean that costs could be in the region

420 of $€ 25$ million per annum. The majority of EU countries ( 16 of 25 reporting data from slaughtered pigs; Alban et al., 2011) are failing to find even a single infected pig. Nearly all of the 1179 positive pigs found in 2010 were from Romania. Thus the programme as it now stands prevents very little human trichinellosis in the EU. This low risk of human Trichinella infection is likely to be due to changes in husbandry with modern intensive pig farms being at very low risk with trichinellosis. It has to be noted 425 that in the $19^{\text {th }}$ century in Germany human trichinellosis was a significant problem with 12500 cases 
reported between 1861 and 1890 (Hinz, 1991) but clearly the factors that promoted transmission of Trichinella to pigs are no longer present making the present programme redundant. Similarly in the USA, where most pork is intensively produced with very low risk of Trichinella infection, there are also very few cases of human trichinellosis (Davies, 2011). Thus, although we have tools to ameliorate

430 transmission to humans these have low cost effectiveness when pork is intensively produced (Table 1)

\subsection{Bovine tuberculosis}

Although not a parasitic disease, many of the principals with regard to cost effectiveness and societal benefit apply to this disease in particular because in high income countries attempts at control

435 are expensive and some proposed methods highly controversial. Bovine tuberculosis is potentially a serious zoonosis and in the past has caused widespread human disease and fatalities in high income countries, and exerts an unknown burden on low income countries. However, the evidence from past case series and the evolving epidemic of bovine tuberculosis in the UK suggests that it is a primarily food-borne disease, with transmission from cattle to humans occurring through the consumption of

440 unpasteurised milk. Consequently, transmission to humans in high income countries, where there is near universal pasteurization of milk, has ceased, even when there remains substantial outbreaks in cattle populations. Indeed, as a public health intervention it has been estimated to cost close to $£ 4$ million per DALY averted (Torgerson and Torgerson, 2010). Of course it is often stated that there are animal health reasons for control, although there are surprisingly little data on the direct costs of bovine

445 TB to animal health and productivity. The real cost to agriculture is the control programme. Arguably the original aims of bovine TB control (i.e. as a public health programme) are being lost with all the legal obligations for control and the trade restrictions that could occur in its absence. In the UK, the policy of badger culling to prevent transmission has been adopted by Government. This is despite evidence of lack of efficacy and poor cost effectiveness (Jenkins et al., 2010). There are better public 
spent by the UK government. Ironically it takes a publication that demonstrates that concurrent infection with $F$. hepatica may reduce the diagnostic efficiency of the bovine tuberculosis test (Claridge et al., 2012) for bovine fasciolosis, an arguably more important animal disease, to be noticed! In low income countries the situation is different. However as it is a food-transmitted disease it is likely that

455 introducing controls in the food chain such as milk pasteurization will be of much greater cost effectiveness than introducing disease control programmes in cattle such as a test and cull policy. In addition, pasteurization of milk will also lower the transmission to humans of other zoonoses such as brucellosis. Thus control and elimination programmes are expensive and may have questionable cost effectiveness, whilst milk pasteurization as a public health policy is cheap and highly effective.

460

\section{Conclusions}

Control of zoonoses is an important part of the "One Health Agenda". As we live in a world of limited resources, control of these disease should be prioritised to those that cause the greatest socio-economic impact, providing that the technology is available to tackle these diseases. Cost effectiveness is a useful

465 tool to prioritise strategies for zoonosis control in terms of cost per DALY averted. This may be in the form of regional or national programmes (such as mass treatment of dogs with praziquantel to reduce transmission of echinococcosis and hence disease burden in humans) or on an individual basis where surveillance and treatment of individual cases may be highly effective, such as with zoonotic human trypanosomiosis. The potential benefits to livestock should be considered and cost benefit calculations

470 can be made to determine if increased productivity is worth the cost of disease control or elimination. In certain diseases the financial benefits of increased animal productivity may more than offset the cost of control and, in addition, effectively reduce or eliminate human disease. This essentially makes the programme free from the public health perspective. Other diseases, particularly some in high income countries attract a lot of resources for control but the societal benefits are marginal and may no longer

475 justify such investment. 
By integrating control of several endemic zoonoses the cost effectiveness may be markedly improved. Regular dog treatment with praziquantel combined with control of stray dog populations, vaccination against rabies and use of insecticidal collars would be of benefit in controlling echinococcosis, rabies and leishmaniosis. These three zoonoses are co endemic over substantial parts of

480 the world and the marginal cost of vaccinating a dog against rabies and supplying an insecticidal collar when they are treated with praziquantel is relatively small as the main costs in such programmes are personnel and infrastructure. There are also new tools becoming available. Vaccinating livestock against E. granulosus is now a reality (Lightowlers, 2006) and modelling suggests that when combined with other measures it may have a strong synergistic effect (Torgerson, 2006). Integrating vaccination

485 of sheep against echinococcosis and brucellosis is also likely to be cost effective as both zoonoses are often highly endemic in the flocks of nomadic pastoralists. Likewise, vaccination of pigs against cysticercosis is likely in the near future (Gauci et al., 2012) and vaccines against Fasciola have shown promise (Dalton et al., 2003). To optimise resources for the control of zoonoses, evidence based studies, some of which have been summarized in the present article, can be used to optimise the agenda

490 for disease control and hence ensure disease control programmes are not only effective but are cost effective and/or have a positive cost benefit.

\section{References}

Alban, L., Pozio, E., Boes, J., Boireau, P., Boué, F., Claes, M., Cook, A.J.C., Dorny, P., Enemark, H.L., Van der Giessen, J., Hunt, K.R., Howell, M., Kirjusina, M., Nöckler, K., Rossi, P., Smith, G.C., Snow, L., Taylor, M.A., Theodoropoulos, G., Vallée, I., Viera-Pinto, M.M., Zimmer, I.A., 2011. Towards a standardised surveillance for Trichinella in the European Union. Prev. Vet. Med. 99, 148-160.

Benner, C., Carabin, H., Sánchez-Serrano, L.P., Budke, C.M., Carmena, D., 2010. Analysis of the economic impact of cystic echinococcosis in Spain. Bull. WHO 88, 49-57.

Bhattarai, R., Budke, C.M., Carabin, H., Proaño, J.V., Flores-Rivera, J., Corona, T., Ivanek, R., Snowden, K.F., Flisser, A., 2012. Estimating the non-monetary burden of neurocysticercosis in Mexico. PLoS Negl. Trop. Dis. 6, e1521.

Budke, C.M., Deplazes, P., Torgerson, P.R., 2006. Global socioeconomic impact of cystic echinococcosis. Emerg. Inf. Dis. 12, 296-303.

Budke, C.M., Jiamin, Q., Qian, W., Torgerson, P.R., 2005. Economic effects of echinococcosis in a 
disease-endemic region of the Tibetan Plateau. Am. J. Trop. Med. Hyg. 73, 2-10.

Budke, C.M., Jiamin, Q., Zinsstag, J., Qian, W., Torgerson, P.R., 2004. Use of disability adjusted life years in the estimation of the disease burden of echinococcosis for a high endemic region of the Tibetan plateau. Am. J. Trop. Med. Hyg. 71, 56-64.

Buxton, D., Innes, E., 1995. A commercial vaccine for ovine toxoplasmosis. Parasitology 110, S11S16.

Carabin, H., Budke, C.M., Cowan, L.D., Willingham, A.L., Torgerson, P.R., 2005. Methods for assessing the burden of parasitic zoonoses: echinococcosis and cysticercosis. Trends Parasitol. 21, 327-333.

Carabin, H., Krecek, R.C., Cowan, L.D., Michael, L., Foyaca-Sibat, H., Nash, T., Willingham, A.L., 2006. Estimation of the cost of Taenia solium cysticercosis in Eastern Cape Province, South Africa. Trop. Med. Int. Health 11, 906-916.

Claridge, J., Diggle, P., McCann, C.M., Mulcahy, G., Flynn, R., McNair, J., Strain, S., Welsh, M., Baylis, M., Williams, D.J.L., 2012. Fasciola hepatica is associated with the failure to detect bovine tuberculosis in dairy cattle. Nat. Commun. 3, 853.

Clausen, J.H., Madsen, H., Murrell, K.D., Van, P.T., Thu, H.N.T., Do, D.T., Thi, L.A.N., Manh, H.N., Dalsgaard, A., 2012. Prevention and control of fish-borne zoonotic trematodes in fish nurseries, Vietnam. Emerg. Infect. Dis. 18, 1438-1445.

Copeman, D.B., Copland, R.S., 2008. Importance and potential impact of liver fluke in cattle and buffalo, in: Overcoming Liver Fluke as a Constraint to Ruminant Production in South-East Asia, Gray, G D, Copland, R. S. and Copeman D. B. (eds). Australian Centre for International Agricultural Research (ACIAR), Canberra, pp. 22-35.

Craig, P.S., Larrieu, E., 2006. Control of cystic echinococcosis/hydatidosis: 1863-2002. Adv. Parasitol. 61, 443-508.

Dalton, J.P., Neill, S.O., Stack, C., Collins, P., Walshe, A., Sekiya, M., Doyle, S., Mulcahy, G., Hoyle, D., Khaznadji, E., Moiré, N., Brennan, G., Mousley, A., Kreshchenko, N., Maule, A.G., Donnelly, S.M., 2003. Fasciola hepatica cathepsin L-like proteases: biology, function, and potential in the development of first generation liver fluke vaccines. Int. J. Parasitol. 33, 11731181.

Davidson, R.M., 2002. Control and eradication of animal diseases in New Zealand. N Z Vet J 50, 6-12. Davies, P.R., 2011. Intensive swine production and pork safety. Foodborne Pathog. Dis. 8, 189-201.

Deplazes, P., Hegglin, D., Gloor, S., Romig, T., 2003. Wilderness in the city: the urbanization of Echinococcus multilocularis. Trends Parasitol. 20, 77-84.

Dorny, P., Praet, N., 2007. Taenia saginata in Europe. VetParasitol 149, 22-24.

Dowdle, W.R., 1998. The principles of disease elimination and eradication. Bull. WHO 76 Suppl 2, 2225.

Dubey, J.P., 2009. Toxoplasmosis in sheep-The last 20 years. Vet. Parasitol. 163, 1-14.

Fasihi Harandi, M., Budke, C.M., Rostami, S., 2012. The monetary burden of cystic echinococcosis in Iran. PLoS Negl. Trop. Dis. 6, e1915.

Fevre, E.M., Von Wissmann, B., Welburn, S.C., Lutumba, P., 2008a. The burden of human African trypanosomiasis. PLoS Negl. Trop. Dis. 2, e333

Fevre, E.M., Odiit, M., Coleman, P.G., Woolhouse, M.E.J., Welburn, S.C., 2008b. Estimating the burden of rhodesiense sleeping sickness during an outbreak in Serere, eastern Uganda. BMC Public Health 8, 96

Finkelstein, J.L., Schleinitz, M.D., Carabin, H., McGarvey, S.T., 2008. Decision-model estimation of the age-specific disability weight for schistosomiasis japonica: a systematic review of the literature. PLoS Negl. Trop. Dis. 2, e158.

Flisser, A., Craig, P.S., Ito, A., 2011. Cysticercosis and taeniosis: Taenia solium, Taenia saginata and Taenia asiactica, in: Oxford Textbook of Zoonoses. Oxford University Press, Oxford, UK, pp. 
$625-642$.

Freyre, A., Bonino, J., Falcón, J., Castells, D., Correa, O., Casaretto, A., 1997. The incidence and economic significance of ovine toxoplasmosis in Uruguay. Vet. Parasitol. 73, 13-15.

Fürst, T., Keiser, J., Utzinger, J., 2012a. Global burden of human food-borne trematodiasis: a systematic review and meta-analysis. Lancet Infect. Dis. 12, 210-221.

Fürst, T., Duthaler, U., Sripa, B., Utzinger, J., Keiser, J., 2012b. Trematode infections: liver and lung flukes. Inf DisClin Nth Am 26, 399-419.

Gauci, C.G., Jayashi, C.M., Gonzalez, A.E., Lackenby, J., Lightowlers, M.W., 2012. Protection of pigs against Taenia solium cysticercosis by immunization with novel recombinant antigens. Vaccine 30, 3824-3828.

Geysen, D., Kanobana, K., Victor, B., Rodriguez-Hidalgo, R., De Borchgrave, J., Brandt, J., Dorny, P., 2007. Validation of meat inspection results for Taenia saginata cysticercosis by PCRrestriction fragment length polymorphism. J. Food Prot. 70, 236-240.

Gilbert, R.E., Freeman, K., Lago, E.G., Bahia-Oliveira, L.M.G., Tan, H.K., Wallon, M., W., B., Stanford, M.R., Petersen, E., 2008. Ocular sequelae of congenital toxoplasmosis in Brazil compared with Europe. PLoS Negl. Trop. Dis. 2, e277.

Greikspoor, A., Sondorp, E., Vos, T., 1999. Cost effectiveness analysis of humanitarian relief interventions: visceral leishmaniasis treatment in the Sudan. Health Policy Plan. 14, 70-76.

Havelaar, A.H., Haagsma, J.A., Mangen, M.-J.J., Kemmeren, J.M., Verhoef, L.P.B., Vijgen, S.M.C., Wilson, M., Friesema, I.H.M., Kortbeek, L.M., Van Duynhoven, Y.T.H.P., Van Pelt, W., 2012. Disease burden of foodborne pathogens in the Netherlands, 2009. Int. J. Food. Microbiol. 156, 231-238.

Hegglin, D., Deplazes, P., 2008. Control strategy for Echinococcus multilocularis. Emerg. Inf. Dis. 14, 1626-1628.

Hinz, E., 1991. Trichinellosis and trichinellosis control in Germany. Southeast Asian J. Trop. Med. Pub. Health 22 Suppl, 329-333.

Hotez, P.J., Fenwick, A., 2009. Schistosomiasis in Africa: an emerging tragedy in our new global health decade. PLoS Negl. Trop. Dis. 3, e485

Hunt McCauley, E., Majid, A.A., Tayeb, A., 1984. Economic evaluation of the production impact of bovine schistosomiasis and vaccination in the Sudan. Prev. Vet. Med. 2, 735-754

Jenkins, D.J., 2006. Echinococcus granulosus in Australia, widespread and doing well! Parasitol Int 55, S203-S206.

Jenkins, H.E., Woodroffe, R., Donnelly, C.A., 2010. The duration of the effects of repeated widespread badger culling on cattle tuberculosis following the cessation of culling. PLoS ONE 5, e9090.

Jones, J.L., Lopez, A., Wilson, M., Schulkin, J., Gibbs, R., 2001. Congenital toxoplasmosis: a review. Obstet. Gynecol. Surv. 56, 296-305.

Kabasa, J.D., 2007. Public-private partnership works to stamp out sleeping sickness in Uganda. Trends Parasitol. 23, 191-192.

Kapel, C.M.O., 2005. Changes in the EU legislation on Trichinella inspection-New challenges in the epidemiology. Vet. Parasitol. 132, 189-194.

Kijlstra, A., Jongert, E., 2009. Toxoplasma-safe meat: close to reality? Trends Parasitol. 25, 18-22.

King, C.H., 2009. Toward the elimination of schistosomiasis. N. Engl. J. Med. 360, 106-109.

King, C.H., Dangerfield-Cha, M., 2008. The unacknowledged impact of chronic schistosomiasis.

Chronic Illn. 4, 65-79.

Kortbeek, L.M., Hofhuis, A., Nijhuis, C.D.M., Havelaar, A.H., 2009. Congenital toxoplasmosis and DALYs in the Netherlands. Mem. Inst. Oswaldo Cruz 104, 370-373.

Koseoglu, E., Yazar, S., Koc, I., 2009. Is Toxoplasma gondii a causal agent in migraine? Am. J. Med. Sci. 338, 120-122.

Lightowlers, M.W., 2006. Cestode vaccines: origins, current status and future prospects. Parasitology 
133 Suppl, S27-42.

Lopez, A.D., Mathers, C.D., Ezzati, M., Jamison, D.T., Murray, C.J., 2006. Global Burden of Disease and Risk Factors. World Bank and Oxford University Press, Washington DC.

Magona, J.W., Walubengo, J., 2011. Mass-treatment and insecticide-spraying of animal reservoirs for emergency control of Rhodesiense sleeping sickness in Uganda. J. Vector Borne Dis. 48, 105108.

Majorowski, M.M., Carabin, H., Kilani, M., Bensalah, A., 2005. Echinococcosis in Tunisia: a cost analysis. Trans. R. Soc. Trop. Med. Hyg. 99, 268-278.

Mariner, J.C., House, J.A., Mebus, C.A., Sollod, A.E., Chibeu, D., Jones, B.A., Roeder, P.L., Admassu, B., van't Klooster, G.G.M., 2012. Rinderpest eradication: appropriate technology and social innovations. Science 337, 1309-1312.

McManus, D.P., Gray, D.J., Li, Y., Feng, Z., Williams, G.M., Stewart, D., Rey-Ladino, J., Ross, A.G., 2010. Schistosomiasis in the People's Republic of China: the era of the Three Gorges Dam. Clin Microbiol. Rev. 23, 442-466.

Murray, C.J., 1996. Rethinking DALYs, in: The Global Burden of Disease: a Comprehensive Assessment of Mortality and Disability from Diseases, Injuries and Risk factors in 1990 and Projected to 2020. Harvard School of Public Health, Cambridge, MA, pp. 1-98.

Murrell, K.D., Pozio, E., 2011. Worldwide Occurrence and Impact of Human Trichinellosis 1986-2009. Emerg. Infect. Dis 17, 2194-2202.

Ndimubanzi, P.C., Carabin, H., Budke, C.M., Nguyen, H., Qian, Y.-J., Rainwater, E., Dickey, M., Reynolds, S., Stoner, J.A., 2010. A systematic review of the frequency of neurocyticercosis with a focus on people with epilepsy. PLoS Negl. Trop. Dis. 4, e870.

Nahorski, W.L., Knap, J.P., Pawłowski, Z.S., Krawczyk, M., Polański, J., Stefaniak, J., Patkowski, W., Szostakowska, B., Pietkiewicz, H., Grzeszczuk, A., Felczak-Korzybska, I., Gołąb, E., Wnukowska, N., Paul, M., Kacprzak, E., Sokolewicz-Bobrowska, E., Niścigorska-Olsen, J., Czyrznikowska, A., Chomicz, L., Cielecka, D., Myjak, P. (2013) Human Alveolar Echinococcosis in Poland: 1990-2011. PLoS Negl. Trop. Dis. 7, e1986.

Palmer, B.S., 2007. Meta-analysis of three case controlled studies and an ecological study into the link between cryptogenic epilepsy and chronic toxoplasmosis infection. Seizure 16, 657-663.

Pappas, G., Roussos, N., Falagas, M.E., 2009. Toxoplasmosis snapshots: global status of Toxoplasma gondii seroprevalence and implications for pregnancy and congenital toxoplasmosis. Int. J. Parasitol. 39, 1385-1394.

Piarroux, M., Piarroux, R., Giorgi, R., Knapp, J., Bardonnet, K., Sudre, B., Watelet, J., Dumortier, J., Gérard, A., Beytout, J., Abergel, A., Mantion, G., Vuitton, D.A., Bresson-Hadni, S., 2011. Clinical features and evolution of alveolar echinococcosis in France from 1982 to 2007: results of a survey in 387 patients. J. Hepatol. 55, 1025-1033.

Pozio, E., 1998. Trichinellosis in the European Union: epidemiology, ecology and economic impact. Parasitol. Today 14, 35-38.

Praet, N., Speybroeck, N., Manzanedo, R., Berkvens, D., Nsame Nforninwe, D., Zoli, A., Quet, F., Preux, P.-M., Carabin, H., Geerts, S., 2009. The disease burden of Taenia solium Cysticercosis in Cameroon. PLoS Negl. Trop. Dis. 3, e406.

Rapsch, C., Schweizer, G., Grimm, F., Kohler, L., Bauer, C., Deplazes, P., Braun, U., Torgerson, P.R., 2006. Estimating the true prevalence of Fasciola hepatica in cattle slaughtered in Switzerland in the absence of an absolute diagnostic test. Int. J. Parasitol. 36, 1153-1158.

Roth, F., Zinsstag, J., Orkhon, D., Chimed-Ochir, G., Hutton, G., Cosivi, O., Carrin, G., Otte, J., 2003. Human health benefits from livestock vaccination for brucellosis: case study. Bull. WHO 81, $867-876$.

Schwabe, C.W., 1984. Veterinary Medicine and Human Health, 3rd ed. Williams \& Wilkins, Baltimore.

Schwarzinger, M., Stouthard, M.E., Burström, K., Nord, E., 2003. Cross-national agreement on 
disability weights: the European Disability Weights Project. Popul. Health Metr. 1, 9.

Schweiger, A., Ammann, R.W., Candinas, D., Clavien, P.-A., Eckert, J., Gottstein, B., Halkic, N., Muellhaupt, B., Prinz, B.M., Reichen, J., Tarr, P.E., Torgerson, P.R., Deplazes, P., 2007. Human alveolar echinococcosis after fox population increase, Switzerland. Emerg. Infect. Dis. 13, 878882.

Schweizer, G., Braun, U., Deplazes, P., Torgerson, P.R., 2005. Estimating the financial losses due to bovine fasciolosis in Switzerland. Vet. Rec. 157, 188-193.

Sripa, B., Kaewkes, S., Intapan, P.M., Maleewong, W., Brindley, P.J., 2010. Food-borne trematodiases in Southeast Asia epidemiology, pathology, clinical manifestation and control. Adv. Parasitol. 72, 305-350.

Torgerson, P.R., 2006. Mathematical models for the control of cystic echinococcosis. Parasitol. Int. 55 Suppl, S253-258.

Torgerson, P.R., Carmona, C., Bonifacino, R., 2000. Estimating the economic effects of cystic echinococcosis: Uruguay, a developing country with upper-middle income. Ann. Trop. Med. Parasitol 94, 703-713.

Torgerson, P.R., Dowling, P.M., 2001. Estimating the economic effects of cystic echinococcosis. Part 2: an endemic region in the United Kingdom, a wealthy, industrialized economy. Ann. Trop. Med. Parasitol. 95, 177-185.

Torgerson, P.R., Dowling, P.M., Abo-Shehada, M.N., 2001. Estimating the economic effects of cystic echinococcosis. Part 3: Jordan, a developing country with lower-middle income. Ann. Trop. Med. Parasitol. 95, 595-603.

Torgerson, P.R., Keller, K., Magnotta, M., Ragland, N., 2010. The global burden of alveolar echinococcosis. PLoS Negl. Trop. Dis. 4, e722.

Torgerson, P.R., Macpherson, C.N.L., 2011. The socioeconomic burden of parasitic zoonoses: global trends. Vet. Parasitol. 182, 79-95.

Torgerson, P.R., Schweiger, A., Deplazes, P., Pohar, M., Reichen, J., Ammann, R.W., Tarr, P.E., Halkik, N., Müllhaupt, B., 2008. Alveolar echinococcosis: from a deadly disease to a well-controlled infection. Relative survival and economic analysis in Switzerland over the last 35 years. J. Hepatol. 49, 72-77.

Torgerson, P.R., Torgerson, D.J., 2010. Public health and bovine tuberculosis: what's all the fuss about? Trends Microbiol. 18, 67-72.

Torrey, E.F., Bartko, J.J., Yolken, R.H., 2012. Toxoplasma gondii and other risk factors for schizophrenia: an update. Schizophr. Bull. 38, 642-647.

Van der Werf, M.J., De Vlas, S.J., Brooker, S., Looman, C.W.N., Nagelkerke, N.J.D., Habbema, J.D.F., Engels, D., 2003. Quantification of clinical morbidity associated with schistosome infection in sub-Saharan Africa. Acta Trop. 86, 125-139.

Wang, L.-D., Chen, H.-G., Guo, J.-G., Zeng, X.-J., Hong, X.-L., Xiong, J.-J., Wu, X.-H., Wang, X.-H., Wang, L.-Y., Xia, G., Hao, Y., Chin, D.P., Zhou, X.-N., 2009. A strategy to control transmission of Schistosoma japonicum in China. N. Engl. J. Med. 360, 121-128.

Wang, L., Utzinger, J., Zhou, X.-N., 2008. Schistosomiasis control: experiences and lessons from China. Lancet 372, 1793-1795.

WHO, 2006. The Control of Neglected Zoonotic Diseases: A Route to Poverty Alleviation. (No. WHO/SDE/FOS/2006.1). World Health Organisation, Geneva.

WHO, 2011. The Control of Neglected Zoonotic Diseases: Community Based Interventions for Prevention and Control. World Health Organisation, Geneva.

Woolhouse, M.E.J., Gowtage-Sequeria, S., 2005. Host range and emerging and reemerging pathogens. Emerg. Infect. Dis. 11, 1842-1847.

Wu, W., Qian, X., Huang, Y., Hong, Q., 2012. A review of the control of clonorchiasis sinensis and Taenia solium taeniasis/cysticercosis in China. Parasitol. Res. 111, 1879-1884. 
Table 1. Relative human burden estimates, economic costs and cost effective tools to prevent human disease.

\begin{tabular}{|c|c|c|c|c|c|c|c|c|c|c|c|c|}
\hline \multicolumn{2}{|c|}{ Component } & \multirow{2}{*}{$\begin{array}{l}\begin{array}{l}\text { Taenia solium } \\
\text { cysticercosis }\end{array} \\
+1+\end{array}$} & \multirow{2}{*}{$\begin{array}{l}\begin{array}{l}\text { Cystic } \\
\text { echinococcosis }\end{array} \\
+++ \\
+++\end{array}$} & \multirow{2}{*}{$\begin{array}{l}\text { Zoonotic African } \\
\text { trypanosomosis } \\
+\end{array}$} & \multirow{2}{*}{ Leishmaniosis } & \multirow{2}{*}{\begin{tabular}{|l|l}
$\begin{array}{l}\text { Zoonotic } \\
\text { schistosomiosis }\end{array}$ \\
$+1++$ \\
\end{tabular}} & \multirow{2}{*}{$\begin{array}{l}\text { Fasciolosis } \\
+\end{array}$} & \multirow{2}{*}{$\begin{array}{l}\text { Other food born } \\
\text { trematodes }\end{array}$} & \multirow{2}{*}{ Toxoplasmosis } & \multirow{2}{*}{$\begin{array}{l}\text { Taenia saginata } \\
\text { Tteniosis } \\
+\end{array}$} & \multirow{2}{*}{$\begin{array}{l}\text { Trichinellosis } \\
+\end{array}$} & \multirow{2}{*}{$\begin{array}{l}\begin{array}{l}\text { Bovine } \\
\text { tuberculosis }\end{array} \\
+\end{array}$} \\
\hline Human & Global & & & & & & & & & & & \\
\hline & Local & $+1+1+$ & $++1+$ & $+1+1+$ & H & $+1++$ & $+1+$ & $+1+1+$ & +1 & + & $+1+$ & $+1+$ \\
\hline \multirow{2}{*}{$\begin{array}{l}\text { Economic } \\
\text { costs in } \\
\text { animals* }\end{array}$} & Global & $+1+$ & + & + & + & $+1+$ & $+1+1+$ & + & +1 & + & + & + \\
\hline & Local & $+1+$ & $+1+$ & $+1+$ & + & $+1+1+$ & $+H+$ & + & $H$ & + & + & + \\
\hline \multicolumn{2}{|c|}{$\begin{array}{l}\text { Cost effective tools } \\
\text { for control or } \\
\text { elimination }\end{array}$} & $+1+1+$ & $+1+$ & + & + & $+1+$ & $+H$ & + & + & + & + & $\begin{array}{l}\text { Elimination in } \\
\text { livestock }\end{array}$ \\
\hline \multicolumn{2}{|c|}{$\begin{array}{l}\text { Cost effective tools to } \\
\text { prevent transmission } \\
\text { to humans }\end{array}$} & $+1+$ & $+1+$ & H & H & $+1+$ & +4 & + & $\begin{array}{l}\text { Freezing or } \\
\text { cooking meat }\end{array}$ & $\begin{array}{l}\text { Freezing or cooking } \\
\text { meat }\end{array}$ & + & $\begin{array}{l}\text { Milk } \\
\text { Pastuerization }\end{array}$ \\
\hline \multicolumn{2}{|c|}{$\begin{array}{l}\text { Cost effectiveness of } \\
\text { treatment of humans }\end{array}$} & H & ++ & $\begin{array}{l}\$ 8.50 \text { per DALY } \\
\text { averted }\end{array}$ & $\begin{array}{l}\$ 18.40 \text { per DALY } \\
\text { averted }\end{array}$ & $+1+$ & $+1+$ & $+1+$ & + & +1 & H & $+111+$ \\
\hline
\end{tabular}

* This includes only the direct and indirect quantifiable costs such as loss of animal productivity due to disease or loss of edible meat and offal due to condemnation in the slaughterhouse. It does not include the costs and effects of control programmes 